\title{
AC 2007-358: SEEKING NEW PRAXIS AND PEDAGOGY: USING ETHNOGRAPHIC RESEARCH METHODS TO TEACH ARCHITECTURAL TECHNOLOGY WITHIN AN INTERNATIONAL SERVICE CONTEXT
}

David Cowan, Indiana University-Purdue University-Indianapolis

David Jan Cowan, Ph.D. Program Coordinator and Assistant Professor: Architectural Technology Design Technology Program Purdue School of Engineering and Technology Indiana University Purdue University Indianapolis

Derek Ogle, Indiana University-Purdue University-Indianapolis

Megan Svarczkopf, Indiana University-Purdue University-Indianapolis 


\title{
Seeking New Praxis and Pedagogy: Using Ethnographic Research Methods to Teach Architectural Technology within an International Service Context
}

\begin{abstract}
Ethnographers rely heavily upon methodologies that require observation and participation in the social actions they attempt to document (Hume and Mulcock ${ }^{1}$ ). Extending these methodologies to architectural technology education requires consideration of their tools of the trade: reflection, videography and journalistic field notes (to name a few) (DeWalt and DeWalt ${ }^{2}$ ). In the particular instance described within this paper, these methods were applied to an international architectural technology course (an undergraduate directed study) that involved the evaluation of post earthquake housing strategies.

This paper looks at the effectiveness of using these strategies to teach students about sustainability, professionalism and construction techniques within a foreign setting. Using a post experience questionnaire, these methods are assessed for their effectiveness as a teaching tool outside the traditional classroom setting.
\end{abstract}

\subsection{Introduction}

This paper examines the application of qualitative research methods to learning experiences gained within an international service learning course situated in Indonesia. It draws heavily upon methods used by ethnographers and, in doing so, looks at the value of these techniques within the context of traditional architectural technology education.

The paper sets the beginnings of the discussion within an undergraduate architectural technology directed study course that was research based. It then examines the types of methods used by ethnographers and explains how these were used in this instance. The discussion advances to an assessment of the value of these methods in teaching architectural technology students.

\subsection{Background}

On May 27, 2006 just before 6:00 AM, a 6.5 magnitude earthquake hit near Jogjakarta (Jogja), Indonesia and its many surrounding villages. This earthquake lasted approximately one minute yet resulted in the deaths of approximately 6,000 people. There was one estimation that 
there were 306,000 to 354,000 homes heavily damaged or destroyed (policy meeting Jogjakarta (Jogja), Indonesia June 26, 2006). It was also stated that there were about 20,000 home based businesses that were affected by this earthquake. Most of the homes that were damaged or destroyed housed the poor, vulnerable, young, or elderly located near or in Bantul, just south of Jogja (see Figure 1).

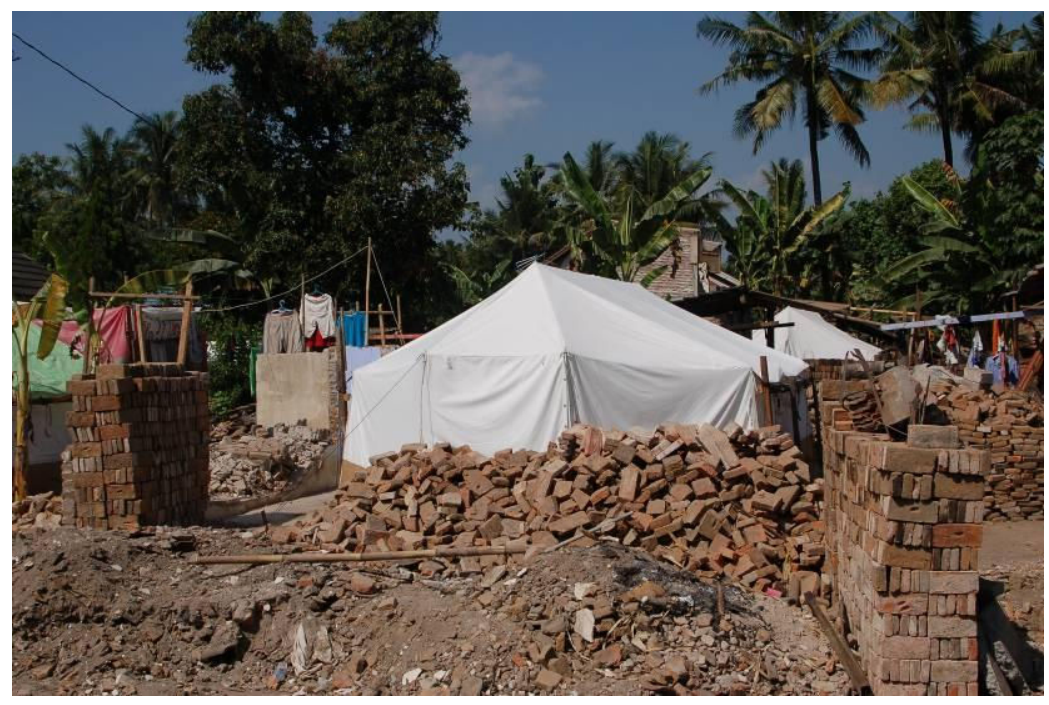

Figure 1: Tent Structures in Earthquake Area

It is within this context that this discussion begins. After attempting all year to send students to a safe haven in Indonesia this particular disaster threw yet another stumbling block into the efforts to visit a country that has had a history of political unrest, terrorism and tsunami devastation. However, armed with extensive local documentation of the events and safety concerns, our journey to this area of the world was approved in June, 2006. Two students from the Design Technology Program at Indianapolis University Purdue University Indianapolis (IUPUI), with support of Undergraduate Research Scholarships, set off, with their mentor, to Indonesia to study disaster reconstruction and sustainable solutions to rebuilding entire communities. 
Our mission was therefore research, education and service directed at helping the victims. However, the environment we were thrown into was chaotic and, just one month after the earthquake, was still suffering from the upheaval of the earth. We therefore had to become extremely versatile in our attempts to gain what could be referred to as slippery data, or information that easily could be overlooked and passed by amongst the bustle of relief activity on the ground. We looked to the methods used mainly by anthropologists to guide us through the overload of images, information and cultural differences.

\subsection{Ethnographic Research Techniques}

$\mathrm{O}^{\prime}$ Reilly $^{4}$ (p.1) notes that: "ethnography is difficult to define because it is used in different ways in different disciplines with different traditions." This was both an attribute and a detriment in this instance as this genre of research embraces many useful techniques for architectural investigation, yet it was cumbersome to sort through, select the ones that best fit, and gain an understanding of how they actually worked. In order to provide depth to the research project, several methods were eventually adopted, in keeping with the triangulation method of research (e.g., Berg ${ }^{5}$, Thyer $^{6}$ ) or multiple operationalism (Krippendorf ${ }^{7}$ ). One example of this technique used in the architectural field is noted by Dana $\operatorname{Cuff}^{8}$ ( p. 6), who, in her research with architectural firms, used a variety of methods - case study, interviews, ethnography - to achieve what she terms "thick description".

The use of ethnographic techniques are not uncommon to architectural research (design), and Cuff's work stands out amongst others that have been directed at studies that look at the qualities of the physical environment and the way people living in these environments experience them (Groat, Wang ${ }^{9}$ ). Much too often, however, the technology side of architecture follows the lead of engineering-like quantitative studies that examine the scientific realm of 
technology. Qualitative research adds color and texture to the field (Shumer ${ }^{10}$ ), creating a whole new praxis and pedagogical area of experimentation.

From the outset, our team realized that we needed to acquire ways and means of documenting our experiences in the field. Ethnography appeared to be a sensible selection in this instance as it (Leedy, Ormrod ${ }^{11}$, p. 137) "looks at an entire group- more specifically, a group that shares a common culture-in depth.” The following sections review ethnographic methods and how they were applied to this particular project. By no means did we avail of all of them. It is also important to note that all of the methods selected, used, in their application, an assignment that forced the participants to recollect upon their daily activities through written or spoken reflection. This is in keeping with the methodology endorsed by many service learning scholars (e.g., Ash, Clayton, and Moses ${ }^{12}$, Schön ${ }^{13}$, and Welch ${ }^{14}$ ).

\subsection{Photo Journalism and Participant Observation}

Photo journalism and participant observation are suitable types of research methods, as noted by Anany and Stroecker ${ }^{15}$ (p.1), to study "in situ" the aftermath of a natural disaster. As Warren ${ }^{16}$ (p. 1) notes as well: "...the visual world becomes another "text" to be read giving clues about the cultures that produce it." These are also methods that are used extensively in ethnographic research practices (e.g., O'Reilly ${ }^{4}$, Wolcott ${ }^{17}$ ).

Willis ${ }^{18}$ (p.113) makes reference to the value of field research and participant observation in the following manner: "Of course, the point of engaging in field work, what impels you to face its difficulties, dilemmas and jeopardizes, is to give yourself the chance of being surprised, to have experiences that generate new knowledge not wholly prefigured in your starting out positions." His statement is particularly appropriate to this context in that he emphasizes that 
ethnographic research follows a path filled with the unexpected surprises that come from observing people.

The approach to using these methods was twofold. First, an effort was made to document, through photographs, the greater part of what was seen each day (e.g., see Figure 2). This was followed by daily discussions of the images that had been captured. These eventually culminated in large, poster-sized visual diaries that were composed once we arrived home (see Figure 3). The editing of these helped us to reflect on what we had learned and to filter the experiences into thematic sections.

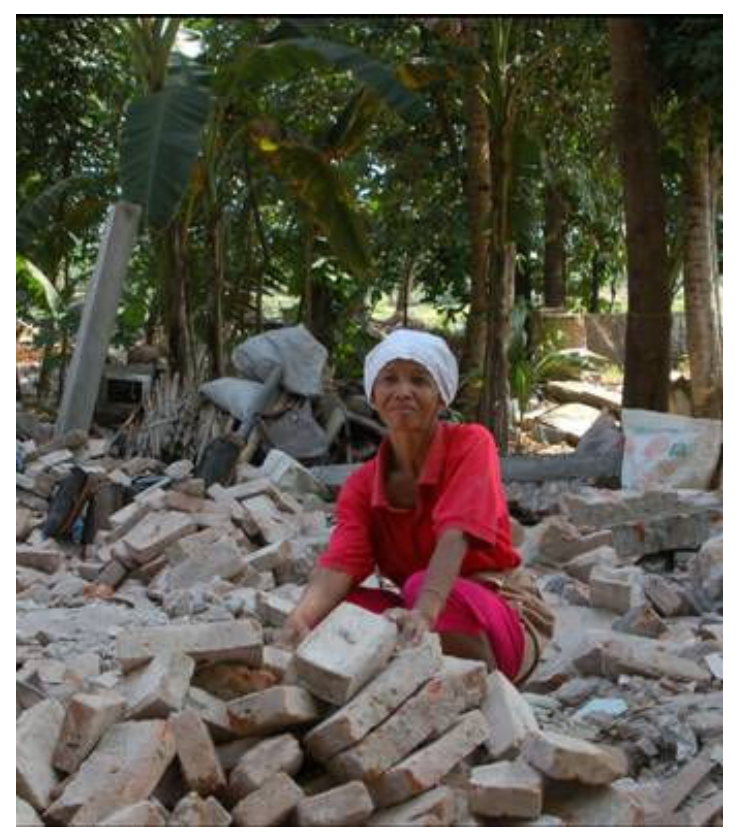

Figure 2: Sorting Through the Rubble: Bantul 


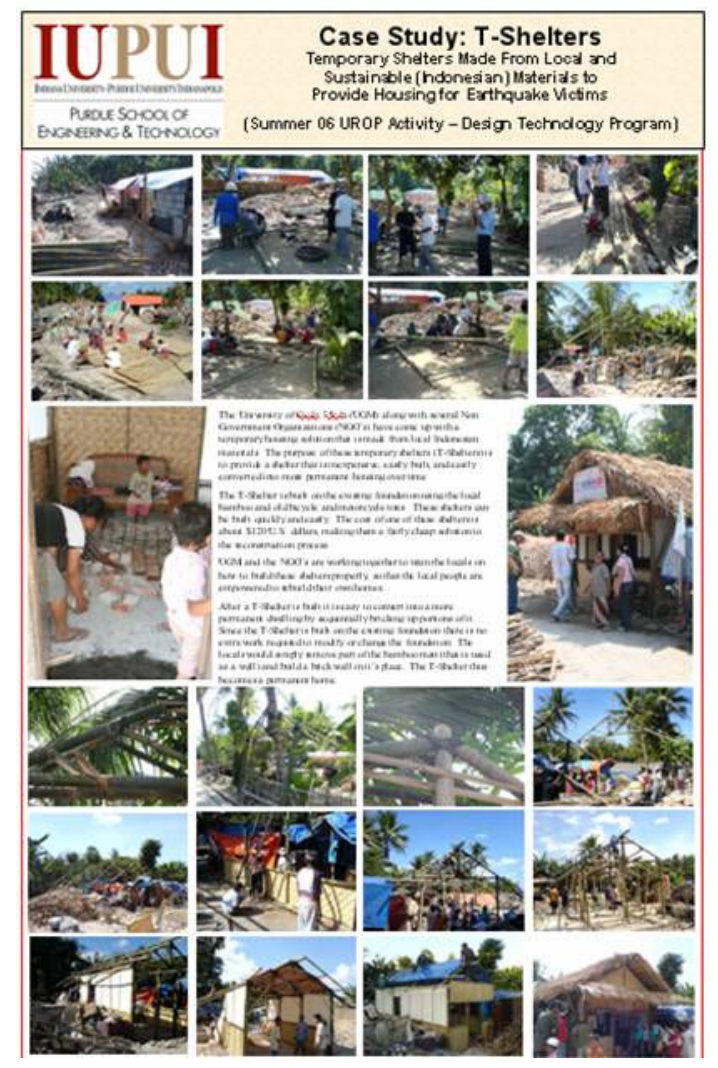

Figure 3: Student Poster (Reflection Assignment)

\subsubsection{Participant Observation}

Participant Observation is, according to Wolcott ${ }^{17}$ (p.44) “...sometimes employed as an umbrella term to describe everything that ethnographers do, and indeed, that all on-site researchers do, in the field." He continues to elaborate (p.46): "Participant observation is founded on first hand experience in naturally occurring events."

Taking these comments into the context of this project, the greatest extent of participant observation was associated with a job shadowing venture. This involved joining a foreign contractor on his rounds through the devastated communities, discussing with the villagers (see Figure 4) their current state of affairs. This was supplemented with photographs, plus a video 
that was initiated in the car at the end of a very busy day. This added to our stores of field data plus allowed for reflecting upon the visual data at a later date.

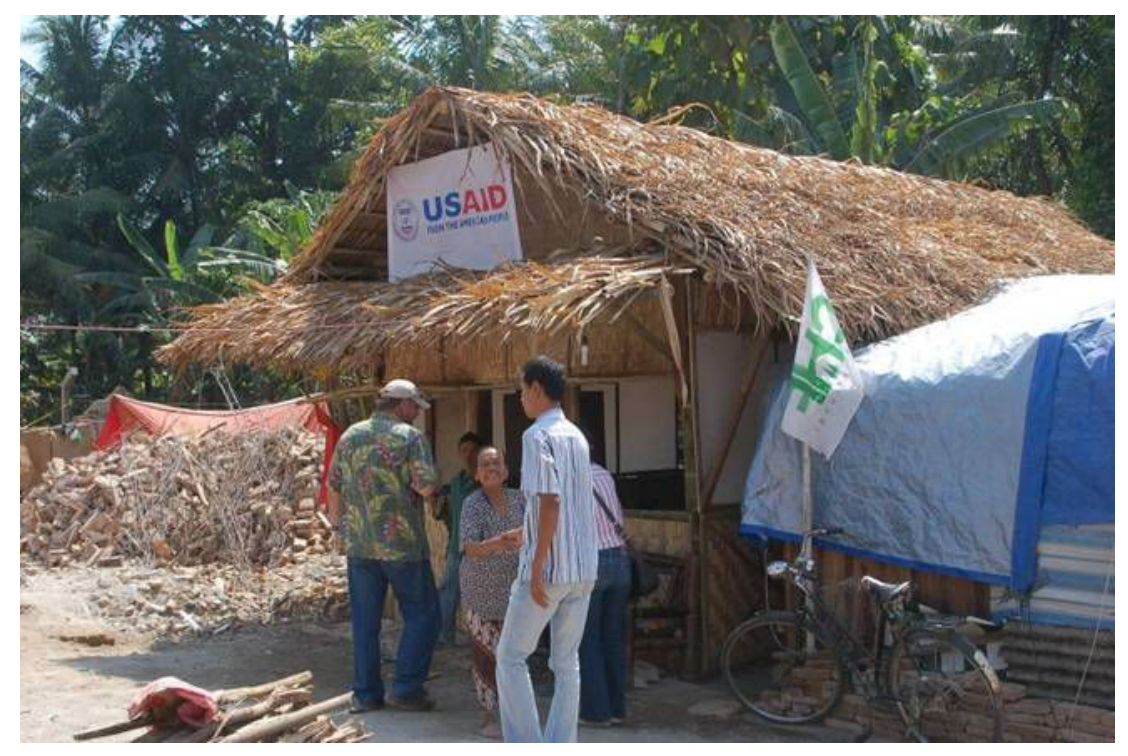

Figure 4: Job Shadowing of USAID Contractor

Other specific instances of participant observation were played out at workshops at the local University (Gadjah Mada School of Architecture and Planning) in Jogja. These provided the opportunity to observe the behaviors of non-governmental organizations (NGO's), scholars and students of disaster reconstruction that congregated at the University's information exchange centers. This provided direct participation in sensitivity training workshops that required teams to attempt to build efficient structures using cylindrical materials (straws) (see Figures 5 and 6). This was an activity that was timed, competitive and highly motivating as a result. This also helped in understanding the unique problems and advantages that building with bamboo (a local and readily available material) created. It also provided the students with an opportunity to later discuss their approach to a competitive activity and how they, as Americans, differed from the 
Indonesian students in their approach to solving building structural problems. Post reflections included a heated debate on the importance of winning and further insights into constructing with bamboo.

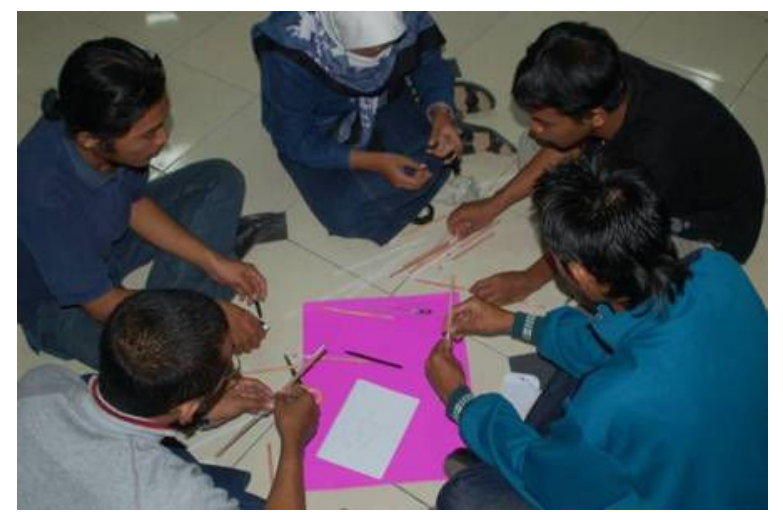

Figure 5: Indonesian Student Activity

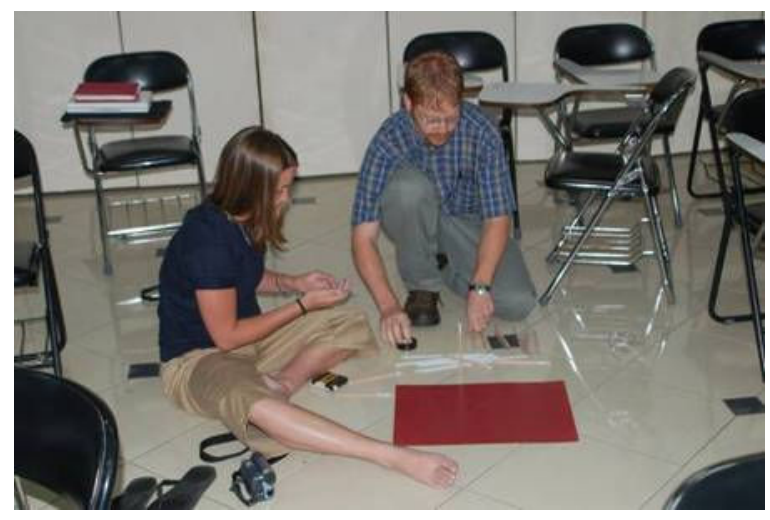

Figure 6: American Student Activity

\subsection{Journal Writing}

Diaries or journals that recount field experience are methods used consistently by ethnographers. O'Reilly ${ }^{4}$, for example, talks about the notion of writing up and writing down. She explains this by indicating that, in the field, information is captured or written down as it happens and as we interpret it. However the writing up stage occurs when the researcher takes the information and begins to organize and frame it within the context of other experiences.

Related to this is the research literature on service learning where Welch ${ }^{14}$, for example, emphasizes that it is not sufficient to tell students to only reflect on their daily experiences. All that this produces are descriptive accounts of personal feelings or experiences, without the level of synthesis that is indicative of higher order thinking (e.g., Bloom ${ }^{19}$ ). Instead, they need a structure that enables them to connect their experiences. 
This type of approach was applied to this project. Prior to embarking to Indonesia, for example, the students were required to complete a short preflection assignment in their journals. To frame their responses they were asked to provide answers to the following questions:

1. What does it mean to be a professional in a foreign country (in the context of what we are about to do)?

2. What do you hope to learn on this trip?

Upon arrival in Jogja, each morning (over breakfast) the students were given questions to respond to in their journals that were intended to frame their journal writing at the end of the day. The value of using this technique was assessed through a questionnaire that was administered after the trip (see Assessment section).

\subsection{Phenomenological Study and Key Informant Interviews}

Leedy and Ormrod ${ }^{11}$ (p.139) refer to phenomenology as "a person's perception of the meaning of an event, as opposed to the event as it exists external to the person." Typically this unfolds through lengthy interviews where the events of the phenomena are revealed. The researcher, during this time, attempts to suspend (bracket) any preconceived notions or personal experiences that may influence what the researcher actually hears.

Interviews are typical examples of phenomenological methods for, as noted by Sproull ${ }^{20}$ (p.192), they are used to acquire insight into a sample group's approach to a particular issue: "questionnaires and interview schedules should be used only when people's attitudes, values and beliefs or self reports are desired or to clarify information". The main purposes of using key informant interviews were to determine attitudes and opinions from local experts on the events that were being captured on video and camera. This helped to reduce the personal bias that comes from editing the world through the lens of a camera. These interviews and videos were 
often situational and spontaneous as it was impossible to determine when and where the experts would be available. Similarly, it was difficult to script the interviews as new events were unfolding day by day and by the minute. Any preconceived notions were reduced as the majority of the experiences were completely unique. As well, the information that was collected was "reporter-like" (phenomenological) and possibly opportunistic and selected based upon what we felt was the most informative story of each day.

\subsection{Self-Reflection: Fire Side Chats and Spontaneous Reflection}

One extension of the use of interviews that we applied in the field was the use of self reflection by means of turning the cameras back upon ourselves each day. These occurred both in the field and in our hotel rooms (fire side chats) at the end of our long days. While in the field we occasionally turned the mike and camera the other way (upon each other) and asked ourselves questions about the surrounding buildings and the new environments we faced: What makes the architecture Indonesian? Why does the earthquake cause certain crack patterns in the walls and roofs? What does it mean to be professional in this environment? (see Figures 7 and 8 ). This forced all of us to think out loud, to get immediate feedback, and to deliver our thoughts knowing that criticism may ensue. This was different from the journal writing where we could compose our thoughts in a private setting, edit them into coherent statements, without the threat of immediate criticism. It also allowed us to reflect upon the journal questions of the day and see if the day's experiences had helped in answering them. 


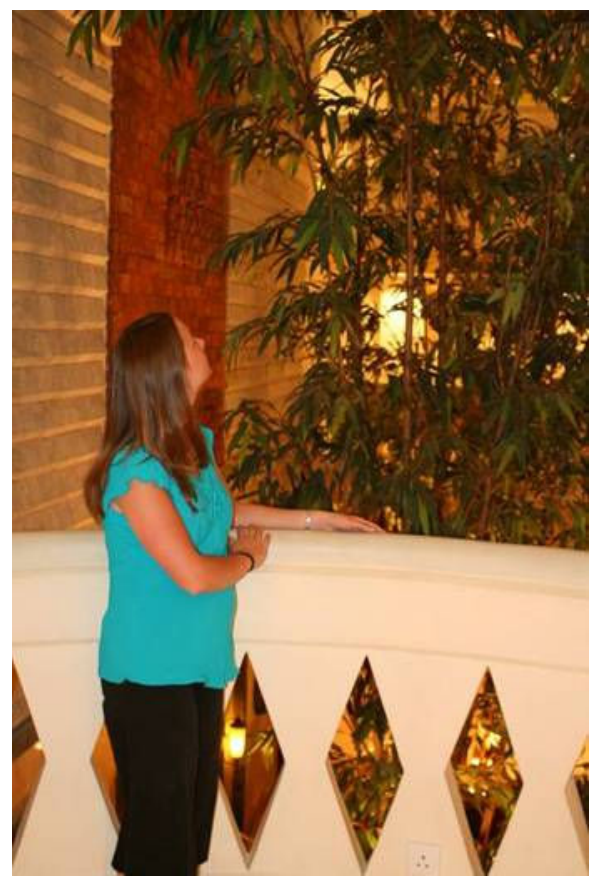

Figure 7: Assessing Indonesian Architecture

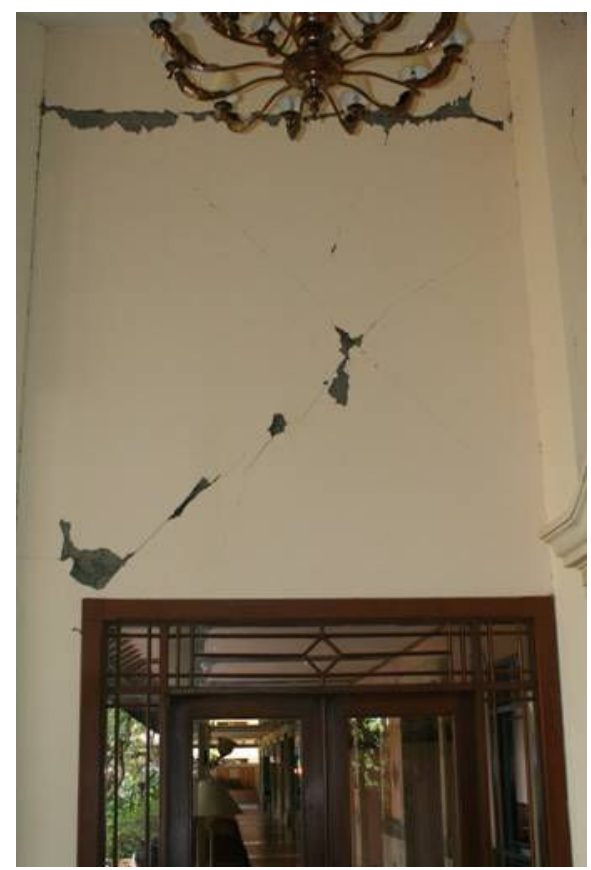

Figure 8: Assessing Earthquake Damage

\subsection{Assessment}

The value of this type of learning and approach to research was assessed by means of a questionnaire directed to the students. The questionnaire was developed in a manner to provide both open and closed answers through the use of a 5 point Likert scale and a section that enabled each person to openly comment on each question (see Appendix A) . The sample group consisted of the two students who were part of the Indonesian venture, so their comments cannot be extended beyond this small group. They do, however, provide a bench mark of insightful, reflective opinion that could be used to guide future studies that involve international, architectural field work. They also extend the suppositions about these teaching and research methods beyond mere personal opinion and conjecture. 


\subsection{Review of Questionnaire Answers}

To summarize the results from each question provides an overview of the student reflections about this type of learning. Their comments also provide insight into the value of their individual experiences and are included herein. Both students first strongly agreed that they learned more about disaster reconstruction than they would have in a regular classroom. Their comments indicate that by being "directly involved with individuals that are currently and have in the past helped in disaster relief efforts" aided them in believing what was being taught to them.

Both participants agreed or strongly agreed that the fire side chats were helpful. One student noted that they "were great in further understanding questions which came to mind at a time that a question couldn't be asked", which leads one to consider that , in this context, the students were able to discuss items in private that they didn't feel comfortable discussing in larger groups. The other interesting comment was: "With these fireside chats I was able to process the things I had experienced and understand them a bit better." In other words, the chats enabled this student to organize reflective thoughts about the experiences and bring them up in a friendly forum where they could be criticized. As the information was being delivered in the field in different languages (English and Bahasa Indonesia) one student also noted that these reflective sessions help to sort out information that the translators may have misinterpreted.

Both strongly agreed that photography enhanced their understanding of the events. The photos served as a visual diary of each day and helped us to clarify items we didn't understand. One student remarked: "After the picture was taken I could look back at them and remember that moment in time, that image that I had seen, and be able to reflect upon the thoughts that went through my head before taking the picture." 
Both agreed or strongly agreed that keeping a daily journal was helpful and that having daily themes to guide their writing were valuable as well. The student comments explained the journal's value as follows: "When I had a daily theme I was able to know what to write down and my thoughts were more focused instead of random rambling." It also aided in their self perception of the quality of their thoughts: "Having guidelines made me think much more in depth about things that I otherwise may not have thought about!"

One of the post-travel activities was to create a poster of the experience, explaining, on one 24 X 36 inch sheet, the key items that defined their experiences in Indonesia. The size of the sheet forced them to edit their words and the images they decided to use (see Figure 3). This led a student to comment as a follows: "This was a nice way to focus everything into one thought that could be shared easily with others." It was yet another means of reflecting upon a learning experience that differed from a journal or an academic paper.

Our use of a camera was not always directed outward at the new culture around us but we often turned the cameras back upon ourselves to force live comments on the scenes that confronted us. One student commented on this as follows: "Although I am not a fan of the pressure, this was definitely true... having the camera on you and being asked a question requires you to think on your feet, and makes you think more in depth the further you discuss it."

Another way of looking at this experience was that it reinforced thinking aloud: "By being put on the spot we had to explain something that we had not always thought out fully, and this forced us to figure out the way we did feel as we were explaining our thoughts. This was not always easy to do, but once we were finished explaining ourselves we typically knew the way we felt." 


\subsection{Summary}

Wolcott ${ }^{17}$ (p. 62) summarizes the value of this type of research as follows:

" The appeal of ethnographic research is that it allows for: a flexible criteria for judging the finished product; provides rich database for further research and writing; emphasizes working with people rather than treating them as objects; can variously emphasize scientific or humanistic aspects."

In this instance it provided the necessary tools to grab the slippery data as it presented itself and led to a wealth of images, interview data and videos that exist as a large data base for future research and educational purposes. The dilemma with researching and teaching disaster construction outside the classroom is that the rich data of the ongoing events changes daily and it must be grabbed as it unfolds or it will be lost. Similarly, given the chaos that surrounds these disasters, the research methods need to be flexible enough to allow for the capturing of events that are extremely organic in nature. In summary, the ethnographic methods employed herein have proven themselves to be an appropriate method to gain data as well as to educate these students about disaster reconstruction. Therein lays the power of the method.

\section{References:}

1. Hume, J., Mulcock,J. (2004). Anthropologists In The Field. New York: Columbia University Press.

2. DeWalt, K., DeWalt, B. (2002). Participant Observation A Guide for Fieldworkers. New York: Altimira Press.

3. Munski, M. (1999). The Architectural Oracles Game: A Futures Tool For Architecture And Design Unpublished Doctoral Thesis. Unpublished doctoral dissertation, University of Michigan.

4. O’Reilly, K. (2005). Ethnographic Methods. New York: Routledge.

5. Berg, B. (2001). Qualitative Research Methods for the Social Sciences. Toronto: Allyn and Bacon.

6. Thyer, B. (2001). The Handbook of Social Work Research Methods. London: Sage Publications.

7. Krippendorff, K. (1980). Content Analysis An Introduction to its Methodology. Newbury Park, California: Sage Publications, Inc.

8. Cuff, D.(1991). Architecture: The Story of Practice. Cambridge: MIT Press.

9. Groat, L., Wang, D. (2002). Architectural Research Methods. New York: John Wiley and Sons Inc.

10. Shumer, R. (2000). Science or Storytellling: How Should We Conduct and Report Service-Learning Research? Michigan Journal of Community Service Learning. Fall 2000, 76-83.

11. Leedy, P., Ormrod, J. (2005). Practical Research Planning and Design. Columbus, Ohio: Pearson Merrill Prentice-Hall,

12. Ash, S.L., Clayton, P.H. \& Moses, M.G. Forthcoming. Teaching and Learning through Critical Reflection: An Instructor's Guide. Sterling, VA: Stylus Publishing. 
13. Schön, D. (1987). Educating the reflective practitioner: toward a new design for teaching and learning in the professions. SanFrancisco: Jossey-Bass.

14. Welch, M. (1999). The ABC's of reflection: A template for students and instructors to implement written reflection in service learning. NSEE Quarterly, 25, 22-25.

15. Ananny, M., Strohecker, C. (2002). Situated Citizen Photojournalism and a Look at Dilemmatic Thinking. Proceedings of the Association for the Advancement of Computing in Education's E-Learn Conference. Montreal, Canada.

16. Warren, S. (2004). Photography and Voice in Critical Qualitative Management Research. Photography and Voice, 861.

17. Wolcott, H.F. (1999). Ethnography a way of seeing. London :Altamira Press.

18. Willis, P. (2000). The Ethnographic Imagination. Malden, MA: Blackwell Publishers.

19. Bloom, B. (1984). Taxonomy of Educational Objectives. Boston, MA: Allyn and Bacon.

20. Sproull, N. (1995). Handbook of Research Methods. London: The Scarecrow Press, Inc. 
Appendix A:

Post Experience Questionnaire

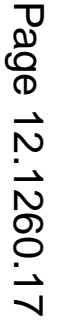


In reference to your experiences in Indonesia in June/July 2006 please comment on the following:

(Please place an " $\mathrm{X}$ " in the box that you feel is the most correct answer)

1. I have learned more about disaster reconstruction than I would have in a regular classroom by participating in this international class.

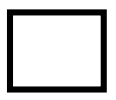

STRONGLY AGREE

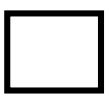

AGREE

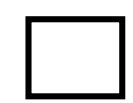

MODERATELY AGREE
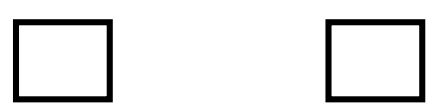

DISAGREE SOMEWHAT TOTALLY DISAGREE

Explain why/why not:

2. I found the use of fireside chats helpful.

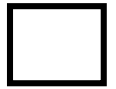

STRONGLY AGREE

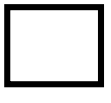

AGREE

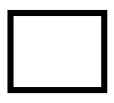

MODERATELY AGREE
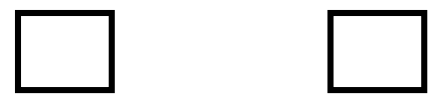

DISAGREE SOMEWHAT TOTALLY DISAGREE

Explain why/why not:

3. Documenting the experiences through photography aided my understanding of the events that I saw.

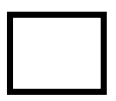

STRONGLY AGREE

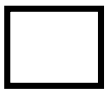

AGREE

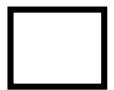

MODERATELY AGREE
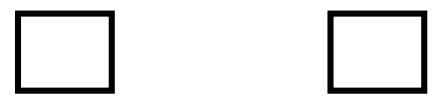

DISAGREE SOMEWHAT TOTALLY DISAGREE

Explain why/why not: 
4. It was helpful to maintain a daily journal.

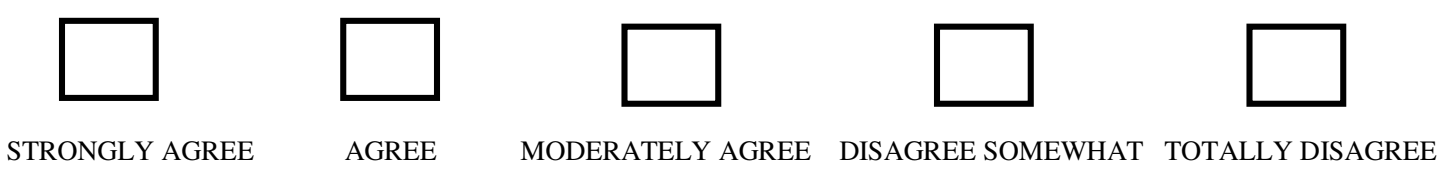

Further Comments:

5. It was helpful to have daily themes that guided the content of my journal reflections.

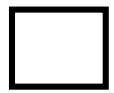

STRONGLY AGREE

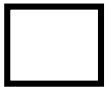

AGREE

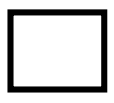

MODERATELY AGREE

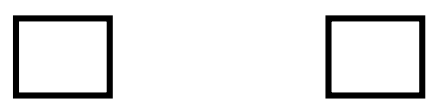

DISAGREE SOMEWHAT TOTALLY DISAGREE

Explain why:

6. Editing the pictures and assembling them into a poster helped me to better reflect upon the experiences I had.

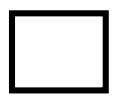

STRONGLY AGREE

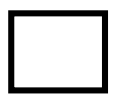

AGREE

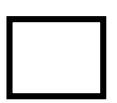

MODERATELY AGREE
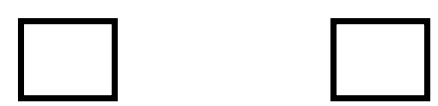

DISAGREE SOMEWHAT TOTALLY DISAGREE

Explain why: 
7. I feel that, having been in this country that I have a better understanding of Indonesian culture than if I had read about it.

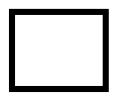

STRONGLY AGREE

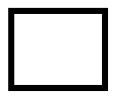

AGREE

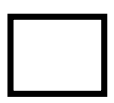

MODERATELY AGREE
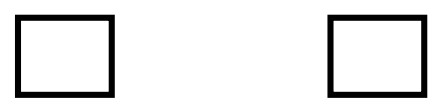

DISAGREE SOMEWHAT TOTALLY DISAGREE

Explain why:

8. I felt, that when the camera was turned on me, and I was forced to interpret (or explain something) (e.g., discussion of Indonesian design in hotel, fire side chats) that this enabled me to think more and reflect more adeptly upon about my experiences in this country.

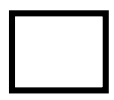

STRONGLY AGREE

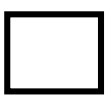

AGREE

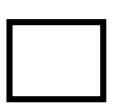

MODERATELY AGREE
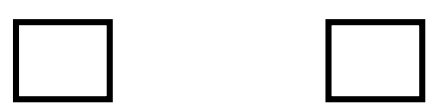

DISAGREE SOMEWHAT TOTALLY DISAGREE

Explain why: 